\title{
O Poder Judiciário \\ no regime democrático
}

FÁBIO KONDER COMPARATO

$\mathrm{N}$ A IDADE MODERNA, só se pode considerar democrático o regime político fundado na soberania popular, e cujo objetivo 'último consiste no respeito integral aos direitos fundamentais da pessoa humana. A soberania do povo, não dirigida à realização dos direitos humanos, conduz necessariamente ao arbítrio da maioria. 0 respeito integral aos direitos do homem, por sua vez, é inalcançável quando o poder político supremo não pertence ao povo.

O Poder Judiciário, como órgão de um Estado democrático, há de ser estruturado em função de ambas essas exigências. R essalte-se, contudo, que, diferentemente dos demais poderes públicos, o Judiciário apresenta uma notável particularidade. Embora seja ele, por definição, a principal garantia do respeito integral aos direitos humanos, na generalidade dos países os magistrados, salvo raras exceções, não são escolhidos pelo voto popular.

$\mathrm{N}$ a verdade, o fator que compatibiliza o Poder J udiciário com o espírito da democracia (no sentido que M ontesquieu conferiu ao vocábulo) é um atributo eminente, o único capaz de suprir a ausência do sufrágio eleitoral: é aquele prestígio público, fundado no amplo respeito moral, que na civilização romana denominavase auctoritas; é a legitimidade pelo respeito e a confiança que os juízes inspiram no povo. O ra, essa característica particular dos magistrados, numa democracia, funda-se essencialmente na independência e na responsabilidade com que o órgão estatal em seu conjunto, e os agentes públicos individualmente considerados, exercem as funções políticas que a C onstituição, como manifestação original de vontade do povo soberano, Ihes atribui.

Se quisermos, portanto, verificar quão democrático é o Poder J udiciário no Brasil, devemos analisar a sua organização e o seu funcionamento, segundo os requisitos fundamentais da independência e da responsabilidade.

São as duas partes em que se divide o presente texto.

\section{Independência}

Esclareçamos, desde logo, o sentido técnico do termo. D iz-se que o Poder J udiciário em seu conjunto é independente, quando não está submetido aos demais Poderes do Estado. Por sua vez, dizem-se independentes os magistrados, quando não há subordinação hierárquica entre eles, não obstante a multiplicidade de instâncias e graus de jurisdição. Com efeito, ao contrário da forma como é estruturada a administração pública, osmagistradosnão dão nem recebem ordens, unsdosoutros. 
A independência funcional da magistratura, assim entendida, é uma garantia institucional do regime democrático. 0 conceito de garantia institucional foi elaborado pela doutrina publicista alemã à época da República de Weimar, para designar as formas de organização dos Poderes Públicos, cuja função é assegurar o respeito aos direitos subjetivos fundamentais, declarados na C onstituição ${ }^{1}$.

D esde a nossa primeira C onstituição republicana, seguimos, em matéria de organização dos Poderes Públicos, o modelo original norte-americano, cujo pressuposto ideológico foi o cuidado em delimitar e restringir a competência do Poder L egislativo, o qual teria, na opinião dos pais fundadores dos Estados U nidos, uma inclinação natural ao abuso de poder. "O corpo legislativo" , escreveu M adison, "estende por toda parte a esfera de sua atividade, e engole todos os poderes no seu turbilhão impetuoso" 2 .

Acrescentou que o Poder Executivo deve ser temido num regime monárquico, ou mesmo quando o povo exerce diretamente a função legislativa.

M as numa república representativa", ponderou, "em que a magistratura executiva é limitada, tanto na extensão, como na duração dos seus poderes, e onde o poder de legislar é exercido por uma assembléia cheia de confiança nas suas próprias forças, pela certeza que tem da sua influência sobre o povo; [...] em tal estado de coisas, é contra as empresas ambiciosas desse poder que 0 povo deve dirigir os seus ciúmes e esgotar todas as precauções ${ }^{3}$.

Acontece que em nosso país - como na generalidade das nações latinoamericanas, de resto - a tradição colonial moldou os costumes políticos no sentido da máxima concentração de poderes na pessoa do C hefe de Estado. Ao adotarmos, pois, o regime presidencial de governo, em que o Chefe de Estado é, ao mesmo tempo, Chefe de Governo, nada mais fizemos do que criar, sob pretexto de uma reprodução do modelo norte-americano, um presidencialismo exacerbado.

Já durante o regime monárquico, aliás, a predominância inconteste da vontade imperial sobre todos os órgãos do Estado, e até mesmo acima da vontade popular, pelo exercício do Poder M oderador, era bem conhecida. Como frisou o $M$ arquês de I taboraí (Rodrigues Torres), "o I mperador reina, governa e administra". Sua M ajestade concentrava em suas mãos todas as prerrogativas do Poder Executivo, o qual, como reconheceu Joaquim $\mathrm{N}$ abuco, sempre foi onipotente, sendo esta onipotência, em suas palavras, "o traço saliente do nosso sistema político" 4 .

$\mathrm{N}$ ão era, assim, de admirar que durante todo o período imperial o J udiciário se apresentasse como fiel servidor do governo. Ele era "uma mola da máquina administrativa", como reconheceu sem disfarces o Visconde de U ruguai ${ }^{5}$. N as palavras candentes de J osé Antonio Pimenta Bueno, o futuro M arquês de São Vicente e o mais autorizado constitucionalista do perío do imperial, "o governo é quem dá as vantagens pecuniárias, os acessos, as honras e as distinções; é quem conserva ou remove, enfim quem dá os despachos não só aos magistrados, mas a seus filhos, parentes e amigos" 6 . 
A Constituição de 1891, procurando corrigir tais abusos, determinou, em seu art. 57, que "os juízes federais são vitalícios e perderão o cargo unicamente por sentençajudicial". A crescentou que "os seus vencimentos serão determinados por lei e não poderão ser diminuídos". M as como a Constituição só se referiu, aí, aos juízes federais, alguns Estados resolveram não observar essas garantias em relação aos seus magistrados. O Supremo Tribunal Federal, chamado a se pronunciar sobre 0 assunto, julgou que as garantias de vitaliciedade, inamovibilidade e irredutibilidade dos vencimentos da magistratura deviam ser observadas, como princípio constitucional, por todos os Estados da federação; o que veio, afinal, a ser consagrado pela reforma constitucional de 1926. No entanto, como tais garantias não se consideravam aplicáveis aos juízes temporários, essa escapatória foi largamente aproveitada, não só pela U nião, como também pelosE stadosfederados.

Consolidou-se, com isto, o costume político, segundo o qual as relações entre o E xecutivo e os demais órgãos estatais não são de potência a potência, mas de quase vassalagem destes para com aquele; ou, mais exatamente, de submissão geral à pessoa do Presidente ou do Governador de Estado; o que representa, de certa forma, a transposição na esfera estatal do tradicional relacionamento do coronel do interior com os seus agregados e capatazes ${ }^{7}$. D a mesma forma, entre o povo e o Estado, personificado na figura do chefe do Executivo, quase nunca se estabelece uma relação de cidadania, mas sim uma situação de dependência ou proteção pessoal, análoga à que existe entre pais e filhos, ou entre padrastos e enteados. 0 povo não foi educado a exercer direitos e a exigir justiça, mas tem sido habitualmente domesticado a procurar auxílios e favores.

É isto o que tende a falsear completamente posição da magistratura judiciária em nossa organização de Poderes. É ingênuo acreditar quea evolução constitucional pôs, finalmente, juízes etribunais ao abrigo da avassaladora hegemonia governamental.

Se quisermos, portanto, garantir a independência do Poder Judiciário, precisamos, sobretudo, protegê-lo contra as indevidas incursões do Executivo em seu território.

É nesse sentido que passo a alinhar algumas sugestões de reforma.

\section{Prenchi mento de cargos nos Tri bu nais}

O Supremo Tribunal Federal deveria ser composto por quinze M inistros, um terço dos quais por indicação do próprio Tribunal, o outro terço indicado pelo M inistério Público Federal e o último terço de indicação da O rdem dos Advogados do Brasil. As indicações seriam sempre feitas em listas tríplices, e a escolha dos M inistros competiria ao Senado Federal, em votação com o quorum qualificado de dois terços dos senadores.

No Superior T ribunal de J ustiça, manter-se-ia a mesma composição prevista no art. 104, parágrafo único, da Constituição, mas a designação dos M inistros incumbiria também ao Senado Federal, deliberando com o mesmo quorum qualificado que se acaba de indicar. 
I gualmente para o Tribunal Superior do Trabalho, manter-se-ia a mesma composição determinada no art. $111, \S 10$, da Constituição ${ }^{8}$, mas as indicações seriam feitas em listas tríplices pelo próprio Tribunal, o M inistério Público do Trabalho e a O rdem dos Advogados do Brasil, com a escolha definitiva sendo feita pelo Senado Federal, nas mesmas condições acima indicadas.

Q uanto aos demais tribunais federais e os tribunais dos E stados e do D istrito Federal, quatro quintos dos seus integrantes deveriam ser escolhidos dentre Juízes de Direito, de modo alternado, por antigüidade e por concurso público, e o quinto restante na forma do disposto no art. 94 da Constituição, ou seja, por membros do M inistério Público, com mais de dez anos de carreira, e de advogados de notório saber jurídico e de reputação ilibada, com mais de dez anos de efetiva atividade profissional, todos eles indicados em lista sêxtupla pelos órgãos de representação das respectivas classes, sendo que, recebidas as indicações, o tribunal formará lista tríplice, a ser submetida ao Senado Federal. Seria, assim, abolido o critério de escolha por merecimento, o qual enseja uma inevitável margem de arbítrio por parte dos tribunais de justiça.

\section{E mendas consti tuci onai s reguladoras da organização, das prer rogati vas e do funci onamento do J udi ciário}

Em se tratando de emendar a Constituição para regular a organização e 0 funcionamento dos Poderes Públicos, bem como para a fixação das prerrogativas dos seus agentes, a proposta deveria ser submetida a referendo popular. $N$ ada é mais característico da consolidada usurpação da soberania do povo, estabelecida entre nós, do que a facilidade com que o impropriamente chamado poder constituinte derivado se atribui a prerrogativa de decidir, em definitivo, assuntos de tanta relevância para a vida democrática.

Em relação ao Judiciário, porém, essa exigência ainda não é bastante. É que, ao contrário dos demais Poderes, el e tem estado, pela tradição constitucional, alheio ao procedimento de emenda ou reforma da Constituição. Entendo que, dada a posição relativamente inferior do J udiciário em relação aos demais Poderes do Estado no equilíbrio constitucional de competências, é indispensável estabelecer a regra de que toda e qual quer proposta de emenda à Constituição, relativa ao Poder J udiciário e à magistratura nacional, seja de iniciativa exclusiva do Supremo Tribunal Federal, analogamente ao que estabelece a Constituição no que concerne ao Estatuto da M agistratura (art. 93).

\section{A utonomia financei ra do Poder Judiciário efixação dossubś di os da magi stratura}

A Constituição Federal, em seu art. 99, estabeleceu a autonomia administrativa e financeira do Poder Judiciário. Isto não impediu, contudo, que o Executivo, pressionado pelo Fundo M onetário Internacional, e com a cumplicidade do Congresso $\mathrm{N}$ acional, promulgasse a chamada L ei de R esponsabilidade Fiscal (L ei Complementar no 101, de 4/ 5/ 2000), que fixou limites intransponíveis 
para as despesas de pessoal do Judiciário, sem que este houvesse participado oficialmente do processo de elaboração da lei.

0 adequado funcionamento da J ustiça para a proteção efetiva da dignidade humana, princípio supremo da ordem jurídica, não se compadece, claro está, com essa visão fiscalista da coisa pública. É indispensável e urgente iniciar uma vigorosa campanha nacional para a fixação, por lei complementar, de um número mínimo de juízes de primeira instância, na U nião, nos Estados e no Distrito Federal, em função do número efetivo de habitantes, e de uma correspondente proporção mínima de magistrados dos tribunais de segunda instância, em relação aos juízes de primeira instância, bem como de um número mínimo de membros dos tribunais superiores, em relação aos integrantes dos tribunais de segunda instância. N unca é demais lembrar que a prestação de justiça é a mais nobre das atividades-fins do Estado, não podendo, portanto, em hipótese alguma, subordinar-se à regra instrumental de balanceamento das contas públicas.

Q uanto à fixação dos subsídios da magistratura, dever-se-ia partir, no plano federal, da regra de que os subsídios dos M inistros do Supremo Tribunal Federal, do Presidente e do Vice-Presidente da R epública, bem como dos D eputados Federais e Senadores seriam fixados conjuntamente pelos representantes desses três Poderes.

Competiria, em seguida, ao Supremo Tribunal Federal fixar os subsídios dos magistrados dos tribunais superiores, dos Tribunais R egionais Federais, dos Tribunais e Juízes E leitorais, dos Tribunais e J uízes do Trabalho, e dos Tribunais e J uízes M ilitares Federais. No plano estadual, haveria análogo procedimento, respeitados os limites máximos fixados pela C onstituição.

\section{I senção política dos magi strados}

U Itimamente, tem-se vulgarizado a prática de magistrados, sobretudo dos tribunais superiores da República, fazerem pronunciamentos públicos sobre assuntos de governo, sem qualquer ligação com os interesses da magistratura nacional.

Será ainda preciso relembrar que tais atitudes contribuem fortemente para destruir o prestígio público e a necessária presunção de imparcialidade que é apanágio dos magistrados? Q uem não percebe, afinal, que, depois de pronunciarse publicamente, fora do contexto de um litígio judicial, contra ou a favor da atuação de governantes ou parlamentares, o magistrado perde a isenção para julgar, eventualmente, causas em que esses governantes ou parlamentares se achem, direta ou indiretamente, envolvidos?

Faz-se mister, portanto, acrescentar à vedação constante do art. 36, inciso III, da atual L ei O rgânica da $\mathrm{M}$ agistratura $\mathrm{N}$ acional ${ }^{9}$, mais uma, concernente a pronunciamentos públicos, feitos por magistrados fora dos processos judiciais, sobre políticas de governo, ou atos de quaisquer agentes públicos, ressalvada a crítica impessoal manifestada em obras doutrinárias ou no exercício do magistério. 


\section{R esponsabilidade}

A essência do regime republicano, como a etimologia indica, é o fato de que o poder político não pertence, como um ativo patrimonial, aos governantes ou agentes estatais, mas é um bem comum do povo. Res publica, res populi, dizia-se em Roma ${ }^{10}$. É só neste preciso sentido que se pode falar em poder público.

O ra, o corolário lógico desse princípio fundamental éa necessária correlação existente entre poder e responsabilidade. Q uanto maior o poder, maior a responsabilidade, entendida esta como o dever que incumbe ao detentor do poder, em nome de outrem, de responder pela forma como o exerce.

A responsabilidade desdobra-se, na verdade, em duas relações: a correspondente ao dever de prestar contas (que na língua inglesa denomina-se accountability) e a relação de sujeição às sanções cominadas em lei pelo mau exercício do poder (liability).

$N$ uma república democrática, os controles institucionais de abuso de poder pelos órgãos do Estado são de duas espécies: o horizontal, ligado ao mecanismo da separação de Poderes, e o vertical, fundado na so berania popular. N a verdade, a democracia éo regime político no qual ninguém, nem mesmo o povo soberano, exerce um poder absoluto, sem controles. 0 poder soberano do povo só pode ser exercido, legitimamente, no quadro da Constituição. E é, justamente, ao Poder J udiciário que incumbe a magna função de interpretar os limites constitucionais dentro dos quais há de ser exercida a soberania popular.

Se assim é, se o próprio povo soberano tem a sua ação limitada nos termos da C onstituição, com maioria de razão deve a atuação do J udiciário ser submetida a uma fiscalização permanente de sua regularidade. O ra, é forçoso reconhecer que os controles institucionais da ação do Judiciário, em nossa sociedade, são muito frouxos e mesmo, em certos setores, praticamente inexistentes.

Comecemos pelo controle horizontal.

Se se exige, com razão, total independência do Judiciário no julgamento dos demais Poderes Públicos à luz dos mandamentos constitucionais e legais, não se compreende por que o corpo de magistrados não deva se submeter, por igual, a um controle externo do seu comportamento por outros órgãos, para efeito de apuração de suas responsabilidades, tanto no nível penal, quanto no civil e no disciplinar.

É falacioso objetar que a fiscalização ab extra da ação dos magistrados importaria na perda de sua independência de julgamento e do seu poder disciplinar interno. Em primeiro lugar, porque esse exame não implica, em hipótese alguma, uma revisão das decisões processuais ou de mérito, dadas por juízes e tribunais. Ele tem por objeto, de um lado, o modo como os magistrados se desempenham no exercício dessa sua função privativa e, de outro lado, a sua conduta pessoal fora dessa atuação funcional. E m segundo lugar, porque o controle externo não pode jamais abranger a competência de julgamento, assim como a censura judicial dos 
atos do Poder Legislativo e do Poder Executivo não significa a assunção pelo J udiciário das funções privativas desses ramos do Estado. E $m$ terceiro lugar, porque um mecanismo de exame externo do funcionamento do J udiciário não acarreta a abolição do poder disciplinar interno dos órgãos judiciais, mas na verdade 0 complementa.

Atualmente, existe um poder censório geral do Judiciário, atribuído ao Conselho $\mathrm{N}$ acional da $\mathrm{M}$ agistratura (Lei O rgânica da $\mathrm{M}$ agistratura $\mathrm{N}$ acional L ei Complementar no 35, de 14/ 3/ 1979). M as esse órgão, constituído por sete $M$ inistros do Supremo Tribunal Federal, tem sido de to do inoperante, pois não dispõe, como é óbvio, da menor condição de exercer a fiscalização do desempenho funcional de todos os juízes e tribunais do país.

Sem dúvida, o mais adequado, numa democracia, é ter a fiscalização não judicial dos Poderes do Estado exercida por um órgão de representação popular. E ntre nós, porém, nenhum dos órgãos legislativos existentes apresenta condições aceitáveis para desempenhar essa função. 0 Senado Federal não representa 0 povo brasileiro, mas sim os Estados federados e o D istrito Federal. E quanto à Câmara dos D eputados e às Assembléias Legislativas, elas mal dão conta das funções que Ihes foram atribuídas pela Constituição, e não suportariam, como é evidente, assumir mais outra, de tão grande complexidade.

0 ideal seria instituir um outro órgão de representação popular, tanto no nível federal, quanto no estadual, com a competência exclusiva de exercer todas as funções de fiscal ização e inquérito atualmente atribuídas aos órgãos legislativos, além da supervisão permanente do funcionamento do Poder Judiciário.

A segunda melhor solução seria instituir, na U nião, em cada Estado e no D istrito Federal, um órgão de controle, composto de agentes das funções essenciais da J ustiça, a saber, o M inistério Público e a advo cacia (nesta incluídas a advocacia e a defensoria públicas). Esseórgão teria a incumbência de verificar o cumprimento, por todos os magistrados, inclusive os M inistros do Supremo Tribunal Federal, dos deveres funcionais declarados em lei (atualmente, arts. 35 e seguintes da L ei O rgânica da $M$ agistratura), e de encaminhar as conclusões de seus inquéritos às autoridades competentes para a aplicação das sanções legais.

$N$ essa ordem de idéias, não parece adequado que, em matéria de crimes comuns, os M inistros do Supremo Tribunal Federal mantenham o privilégio de serem julgados pelos seus pares. Poder-se-ia, assim, cogitar da criação de um órgão judiciário especial para tais casos, composto pelos cinco $\mathrm{M}$ inistros mais antigos em atuação no Superior Tribunal de Justiça.

N o tocante ao controle vertical da atuação da magistratura, convém recordar que a Carta Política do I mpério, em seu art. 157, instituiu uma ação criminal contra os juízes de direito, "por suborno, peita, peculato e concussão", a qual poderia ser intentada "dentro de ano e dia pelo próprio queixoso, ou por qualquer do Povo, guardada a ordem do Processo estabelecida na Lei". 
Sem dúvida, essa espécie de ação popular criminal, limitada exclusivamente à hipótese em que o réu é magistrado, não mais se justifica nos dias atuais. Conviria, no entanto, criar uma ação popular criminal subsidiária, mediante adaptação do disposto no art. 50 , inciso LIX, da Constituição Federal ${ }^{11}$, toda vez que o réu seja um agente público. Em tal hipótese, a ação penal subsidiária deveria ser admitida, ainda quando o representante do Ministério Público se recusasse, expressamente, a oferecer a denúncia.

Por outro lado, não se deve nunca esquecer de garantir cumpridamente a todos os jurisdicionadoso respeito ao direito fundamental de obter, no J udiciário, um julgamento isento.

$\mathrm{N}$ esse sentido, proponho a adoção de uma providência processual simples, a fim de resolver o problema - assaz freqüente, aliás - de os jurisdicionados se encontrarem efetivamente privados do direito de serem julgados de forma imparcial na comarca em que são domiciliados. Suponha-se a hipótese de um juiz de direito que, em região de agudo conflito agrário, coloque-se objetivamentede modo intencional ou não, pouco importa - do lado dos proprietários rurais, e se empenhe em distribuir, mais a torto que a direito, condenações criminais a mancheias contra todos os que atuem, direta ou indiretamente, a favor da reforma agrária; além de julgar sistematicamente improcedentes as ações possessórias e reipersecutórias intentadas por essas mesmas pessoas. As regras processuais concernentes à suspeição não têm aí aplicação, em princípio, pois não se consegue provar algum interesse pessoal do magistrado na solução das lides submetidas à sua decisão.

Para a solução de casos dessa natureza, poder-se-ia cogitar de atribuir a qualquer parte em juízo, em qualquer espécie de processo, o direito de obter 0 desaforamento do feito para o juízo que vier a ser designado pelo tribunal de segunda instância. Seria um direito potestativo, exercitável, portanto, sem que o seu titular tenha que alegar motivo algum. A freqüência com que for exercido esse direito, em determinado juízo, serviria como indício de que o magistrado já não goza da indispensável confiança dos jurisdicionados, havendo perdido a sua auctoritas funcional.

Eis aí as sugestões que me parecem importantes e oportunas oferecer à consideração geral, como subsídio aos trabalhos de aperfeiçoamento da organização do Poder Judiciário em nosso país.

N otas

1 Sobre 0 assunto vejam-se, na doutrina brasileira, Paulo Bonavides, C urso de Direito Constitucional, 7ạ ed., M alheiros Editores, capítulo 15, e na doutrina alemã contemporânea, Klaus Stern, D asStaatsrecht der Bundesrepublik D eutschland, t. III / 1, M ünch, Verlag C. H. Beck, 1988, 68.

2 The Federalist, ensaio no 48, N ew York, The M odern Library, p. 322. 
3 I dem, pp. 322-323.

4 U m Estadista do I mpério, Rio de Janeiro, N ova Aguilar, p. 239.

5 Ensaio sobre o Direito A dministrativo, Rio de Janeiro, Typographia $\mathrm{N}$ acional, t. II, 1862, p. 261.

6 A pontamentos sobre o Processo Criminal Brasileiro, 2ª ed., Rio de Janeiro, 1857, p. 39.

7 Relembre-se o já clássico ensaio de Victor N unes Leal, Coronelismo, Enxada eVoto, cuja 1 a edição é de 1949.

8 "O Tribunal Superior do Trabalho compor-se-á de dezessete M inistros, togados e vitalícios, escolhidos dentre brasileiros com mais de trinta e cinco e menos de sessenta e cinco anos, $[\ldots]$ dos quais onze escolhidos dentre juízes dos Tribunais R egionais do Trabalho, integrantes da carreira da magistratura trabalhista, três dentre advogados e três dentre membros do M inistério Público do Trabalho."

9 “É vedado ao magistrado: [...] III - manifestar, por qualquer meio de comunicação, opinião sobre processo pendente de julgamento, seu ou de outrem, ou juízo depreciativo sobre despachos, votos ou sentenças, de órgãos judiciais, ressalvada a crítica nos autos e em obras técnicas ou no exercício do magistério."

10 Cícero, De republica, I, XXV, 39.

11 “Será admitida ação privada nos crimes de ação pública, se esta não for intentada no prazo legal".

Fábio K onder Comparato é professor-titular da Faculdade de Direito da U niversidade de São Paulo, doutor honoris causa da U niversidade de Coimbra e doutor em D ireito pela U niversidade de Paris.

Texto recebido e aceito para publicação em 19 de junho de 2004. 